\title{
Production of Titanium Alloys for Advanced Aerospace Systems by Powder Metallurgy
}

\author{
Vinicius André Rodrigues Henriques ${ }^{\text {a*, Pedro Paulo de Campos, }}$ \\ Carlos Alberto Alves Cairo ${ }^{\text {a }}$ José Carlos Bressiani ${ }^{\mathrm{b}}$ \\ aDivisão de Materiais do Instituto de Aeronáutica e Espaço - AMR/IAE/CTA \\ ${ }^{\mathrm{b}}$ Instituto de Pesquisas Energéticas e Nucleares - IPEN/CNEM - SP
}

Received: July 19, 2004; Revised: April 19, 2005

\begin{abstract}
Titanium alloys parts are ideally suited for advanced aerospace systems because of their unique combination of high specific strength at both room temperature and moderately elevated temperature, in addition to excellent corrosion resistance. Despite these features, use of titanium alloys in engines and airframes is limited by cost. The alloys processing by powder metallurgy eases the obtainment of parts with complex geometry. In this work, results of the Ti-6Al-4V and Ti-13Nb-13Zr alloys production are presented. Samples were produced by mixing of initial metallic powders followed by uniaxial and cold isostatic pressing with subsequent densification by sintering between 900 up to $1500^{\circ} \mathrm{C}$, in vacuum. Sintered samples were characterized for phase composition, microstructure and microhardness by X-ray diffraction, scanning electron microscopy and Vickers indentation, respectively. It was shown that the samples were sintered to high densities and presented homogeneous microstructure from the elements dissolution with low interstitial pick-up.
\end{abstract}

Keywords: powder metallurgy, titanium alloys, near-net-shape

\section{Introduction}

Over the last decade, the focus of titanium alloy development has shifted from aerospace to industrial applications. However, the titanium industry will still dependent on the aerospace market and this sector will constitute a significant percentage of total consumption for years to come. The metallurgy of titanium and Ti-base alloys has been intensely investigated in the last 50 years. Titanium has unique properties like its high strength-to-weight ratio, good resistance to many corrosive environments and can be used over a wide range of temperatures. Typical engineering applications of titanium alloys include the manufacture of cryogenic devices and aerospace components. The high buy-to-fly ratio associated with many titanium components, combined with forging and machining difficulties and recent availability problems, has led to a strong drive for near-net titanium fabrication. A very promising method of attaining this goal is powder metallurgy $(\mathrm{P} / \mathrm{M})^{1}$.

The primary justifications for using titanium in the aerospace industry are $^{2}$ :

- weight savings (primarily as a steel replacement);

- space limitation (replace Al alloys);

- operating temperature (Al, Ni, steel alloys replacement);

- corrosion resistance (replace $\mathrm{Al}$ and low alloy steels); and

- composite compatibility (replace Al alloys).

Weight savings is due to the high strength-to-weight ratio. The lower density of titanium compared with steel permits weight savings, replacing steels even though they may be higher strength. As the strength of titanium alloys is significantly higher than $\mathrm{Al}$ alloys, weight savings can be achieved in their replacement in spite of the $60 \%$ higher density, assuming that the component is not gage limited ${ }^{3}$.

Titanium could also replace aluminum when the operating temperature exceeds about $130{ }^{\circ} \mathrm{C}$, which is the normal maximum operating temperature for conventional aluminum. These conditions exist, for example, in the nacelle and auxiliary power unity (APU) areas and wing anti-icing system for airframe structures. Steel and nickel-base alloys are obvious alternative, but they have a density about 1.7 times that of titanium ${ }^{4-5}$.

Corrosion resistance can be a very important issue. The corrosion resistance of titanium is such that corrosion protective coatings or paints are not required. (paint is applied when titanium comes into contact with an aluminum or low alloy steel component to prevent galvanic corrosion of the contact material). Much of the floor support structure under the galleys and lavatories is in a very corrosive environment which dictates the use of titanium to provide high structural durability ${ }^{4}$.

Polymer matrix composite (PMC) compatibility is becoming a bigger issue with higher utilization of composite structure on aircraft. The titanium is galvanically compatible with the carbon fibers in the composites, whereas aluminum (and low ally steels) and carbon generate a significant galvanic potential. The selection of titanium in these instances is related to the criticality of the structure ${ }^{2}$.

Cost is always an important consideration. The raw material may cost anywhere from 3 to times as much as steel or aluminum, and the machining costs for titanium are generally significantly higher than for the other materials (at least 10 times that to machine $\mathrm{Al}$ ). In that sense, the titanium alloys production by powder metallurgy, starting from the elemental or prealloyed powders is a feasible route considering its lower costs, versatility and also allowing to manufacture parts with complex geometry and near the final dimensions $s^{6-7}$.

The importance of the microstructural development stay on the establishment of optimized microstructural conditions, aiming the parts production with the best properties. Ti-6Al-4V is the most 
widely used titanium alloy and accounts for nearly $45 \%$ of total titanium production. Ti-13Nb-13Zr is a promising candidates for aerospace and military applications ${ }^{8-10}$.

\section{Experimental}

The blended elemental method followed by a sequence of uniaxial and cold isostatic pressing with subsequent densification by sintering was chosen for the preparation of the alloys.

Titanium and zirconium powders were obtained by the $\mathrm{HDH}$ technique. Hydriding was carried out at $500{ }^{\circ} \mathrm{C}$ in a vertical furnace for 3 hours under a positive pressure. After cooling to room temperature, the friable hydride was milled in a niobium container without protecting atmosphere. The dehydriding stage was carried out at $500{ }^{\circ} \mathrm{C}$ in dynamic vacuum conditions. Niobium and zirconium powders was obtained using the same route, however, hydriding-dehydriding temperatures were significantly higher $\left(800^{\circ} \mathrm{C}\right)$. Aluminum and vanadium powders were supplied by Valimet and Alpha Aesar, respectively. Table 1 shows the principal characteristics of those powders.

Table 1. Characteristics of the powders used in the alloys preparation.

\begin{tabular}{llllll}
\hline \multicolumn{1}{c}{ Characteristic } & $\mathrm{Ti}$ & $\mathrm{Nb}$ & $\mathrm{Al}$ & $\mathrm{V}$ & $\mathrm{Zr}$ \\
\hline Particles size $(\mu \mathrm{m})$ & 10 & 9 & 33 & 30 & 10 \\
Morphology & $\mathrm{Ang}^{\mathrm{a}}$ & $\mathrm{Ang}^{\mathrm{a}}$ & $\mathrm{Sph}^{\mathrm{b}}$ & $\mathrm{Ang}^{\mathrm{a}}$ & $\mathrm{Ang}^{\mathrm{b}}$ \\
Melting point $\left({ }^{\circ} \mathrm{C}\right)$ & 1670 & 2468 & 660 & 1890 & 1850 \\
\hline
\end{tabular}

ang - Angular

a Sph - Spherical

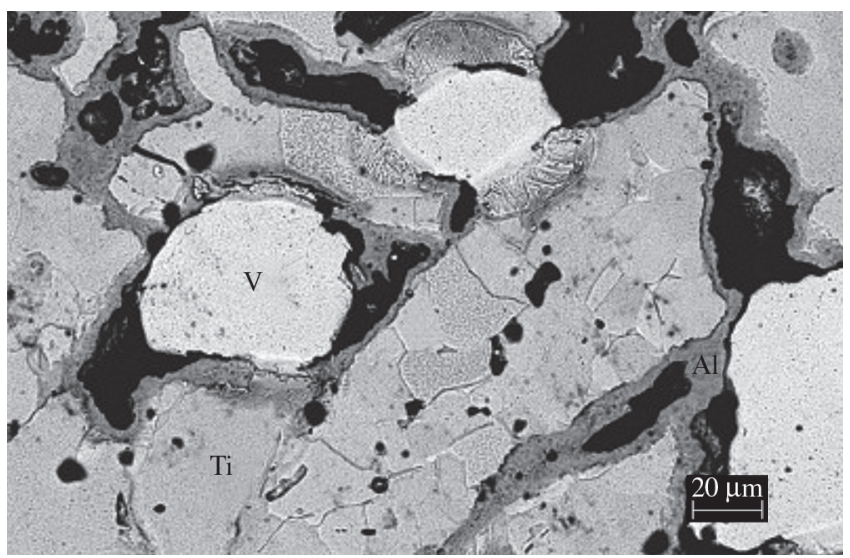

(a) $900{ }^{\circ} \mathrm{C}$

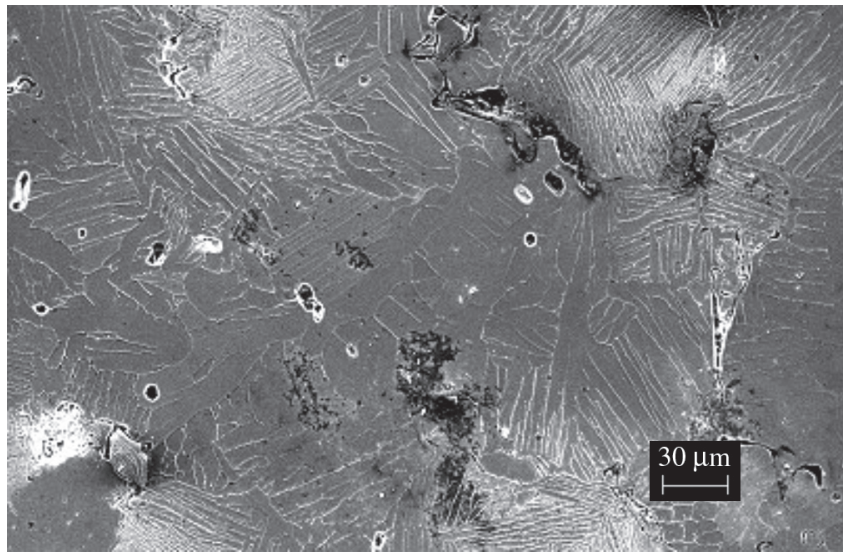

(c) $1300{ }^{\circ} \mathrm{C}$
The starting powders were weighed (10 grams) and blended for 15 minutes in a double-cone mixer. After blending, powders were cold uniaxially pressed under pressure of $80 \mathrm{MPa}$, in cylindrical $20 \mathrm{~mm}$ diameters steel dies. Afterwards, samples were encapsulated under vacuum in flexible rubber molds and cold isostatically pressed (CIP) at $300 \mathrm{MPa}$ during 30 seconds in an isostatic press.

Sintering was carried out in titanium crucible in high vacuum condition $\left(10^{-6}\right.$ Torr $)$, using a Thermal Technology Inc. model Astro 1000 equipment. Sintering temperatures ranged between 900 and $1500{ }^{\circ} \mathrm{C}$ and heating rates of $20{ }^{\circ} \mathrm{C} / \mathrm{min}$. After reaching the nominal temperature, samples were hold at the chosen temperature for 1 hour and then furnace cooled to room temperature. Metallographic preparation was carried out using conventional techniques. Specimens were etched with a Kroll solution: (3 mL HF: $6 \mathrm{~mL} \mathrm{HNO}_{3}$ : $100 \mathrm{~mL} \mathrm{H}_{2} \mathrm{O}$ ) to reveal its microstructure. Microhardness measurements were carried out in a Micromet 2004 equipment, Buehler, with load of $0.2 \mathrm{kgf}$. The photomicrographs were obtained using a SEM LEO model 435VPi. The density of the sintered samples was determined by the Archimedes method.

\section{Results and Discussion}

The samples has presented high densification, varying between 69 and $71 \%$ of the theoretical specific mass, after cold isostatic pressing and, among 93 and 95\%, after sintering, with homogeneous microstructure.

The specimens of the Ti-6Al-4V (Figure 1) presented a Widmanstätten-like microstructure, two-phase $(\alpha+\beta)$, with low porosity. The amount of the Widmanstätten-like microstructure increased

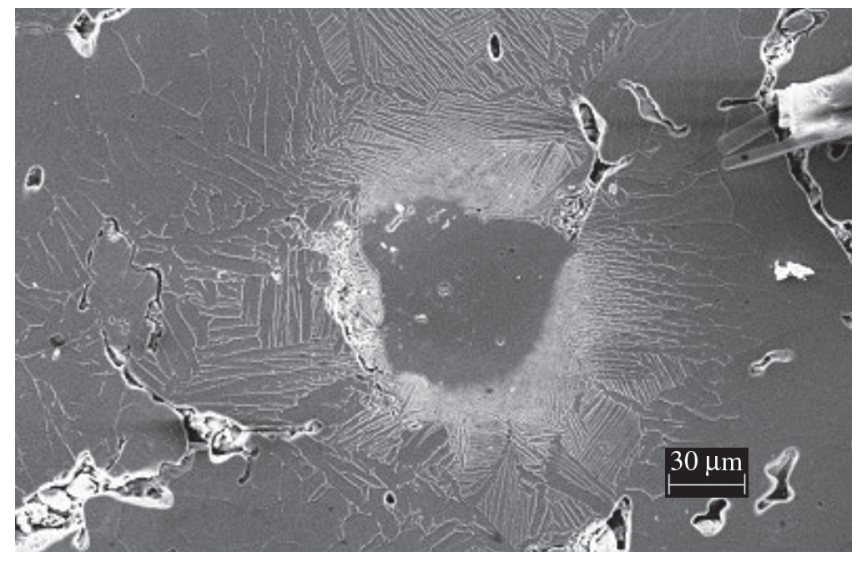

(b) $1100{ }^{\circ} \mathrm{C}$

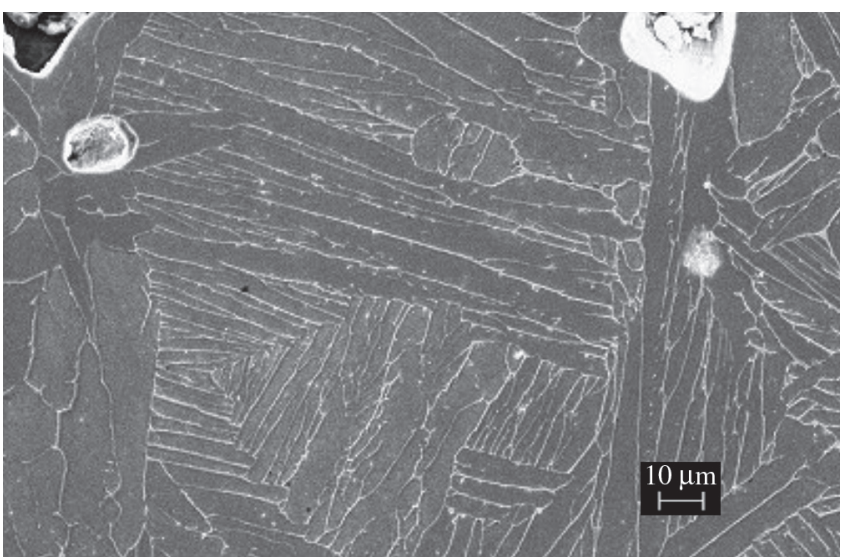

(d) $1500{ }^{\circ} \mathrm{C}$

Figure 1. Microstructural development of P/M-Ti-6Al-4V alloy showing the Widmanstätten growing from vanadium dissolution between 900 to $1500{ }^{\circ} \mathrm{C}$. 
with increase of the sintering temperature and with the decrease of the heating rate. The values of hardness, were function of the sintering temperature, lying in the range from 370 to $400 \mathrm{HV}$ for the specimens prepared at $1500{ }^{\circ} \mathrm{C}$. At lower sintering temperatures, the obtained microstructure is inhomogeneous and display coarse porosity. The hardness commonly reported for hot wrought alloys is about $350 \mathrm{HV}^{1}$.

The Ti-6Al-4V specimens sintered at $1500{ }^{\circ} \mathrm{C}$, presented the best results when compared to the microstructure found in commercial samples. It can be observed, a Widmanstätten-like microstructure distributed throughout the specimen (Figure 1). Concerning the Widmanstätten microstructure, the dark-contrasting areas are $\alpha$-phase plates. The $\beta$-phase, present among $\alpha$-plates, gives rise to a white contrast.

In the Ti-6Al-4V, at $1000{ }^{\circ} \mathrm{C}$, begins the formation of the twophase Widmanstätten structure starting from the vanadium particles, that act as $\beta$-phase nucleator agent. It can be observed that the Widmanstätten structure grows with the dissolution of the $\beta$-stabilizators particles by increase of the sintering temperature.

The furnace-cooling produced a coarse Widmanstätten microstructure characterized by colonies of $\alpha$ platelets oriented along crystallographic variants. Both microstructures contained continuos and discontinuous $\alpha$ along prior grain boundaries. The size of the $\alpha$ platelets increased as the alloy compositions became comparably richer in $\alpha$ stabilizing aluminum. This increase in $\alpha$ platelet size reflects an reduction in the growth kinetics of the $\beta$-phase with increasing $\alpha$ stabilizer content. This way, Ti-6Al-4V samples has showed a lower $\beta$-phase content as observed in the microstructure.
This fact, obviously, will affect the final properties of the alloys, improving the strength.

The Ti-13Nb-13Zr alloy was recently developed and is classified as near- $\beta$ type. This titanium alloy presents low modulus of elasticity allied at the higher values of mechanical resistance.

The microstructure analysis (Figure 2) shows that the Widmanstätten structure grows with the dissolution of the niobium particles, that act as $\beta$-phase nucleator agent, by increase of the sintering temperature. At $1500{ }^{\circ} \mathrm{C}$, a homogeneous microstructure, consisting of $\alpha$ plates (Widmanstätten) and hcp-martensite $\left(\alpha^{\prime}\right)$ dispersed in $\beta$ matrix is observed.

The martensite presence seems to demonstrate that the alloy is more likely an $(\alpha+\beta)$ alloy instead of a near- $\beta$ alloy. The final microstructure is defined by the control of the $\beta$ phase precipitation in the cooling, that can be retained, to transform into martensitic structures or then allotropicly transform into the $\alpha$ phase. Concerning the alloy microstructure, the dark-contrasting areas are $\alpha$-phase plates. The $\beta$-phase, present among the $\alpha$-phase areas, gives rise to a white contrast.

The samples presented hardness values around $300 \mathrm{HV}$, next to the observed in samples produced by the conventional methods (melting).

The Figure 3 shows the $\alpha$ and $\beta$ areas (at $1500{ }^{\circ} \mathrm{C}$ ) where the analyses for EDS were carried out. Table 2 presents the result of the quantitative analysis of the elements.

The Table 2 shows that the niobium presents a superior content in $\beta$-phase, due its power of preferential stabilization of this phase.

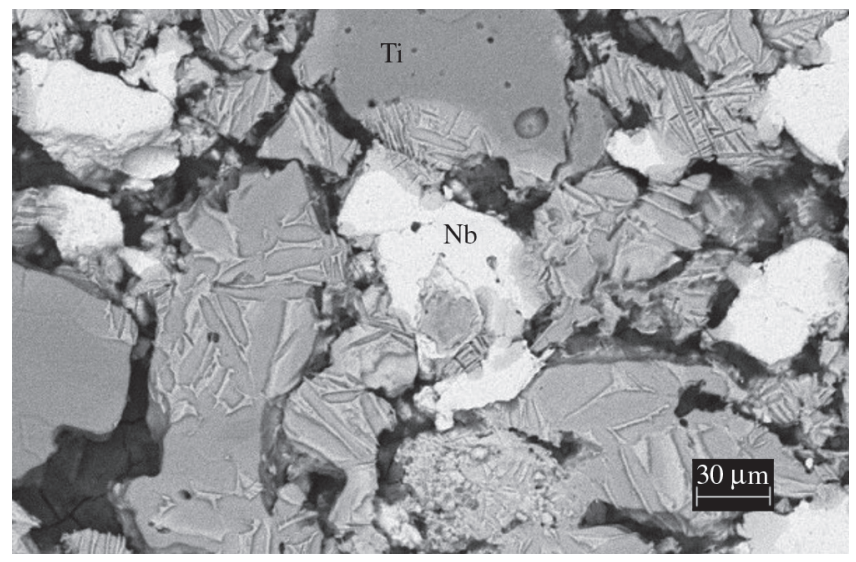

(a) $900{ }^{\circ} \mathrm{C}$

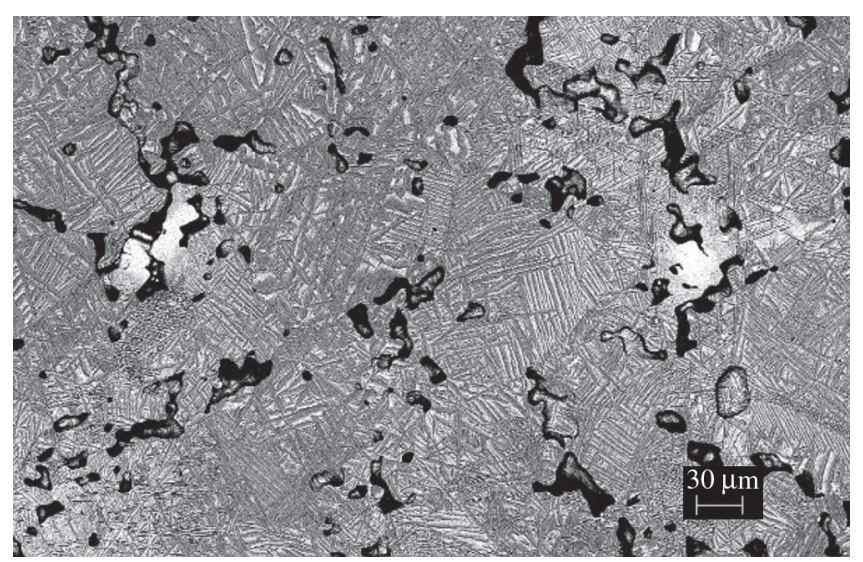

(c) $1300{ }^{\circ} \mathrm{C}$

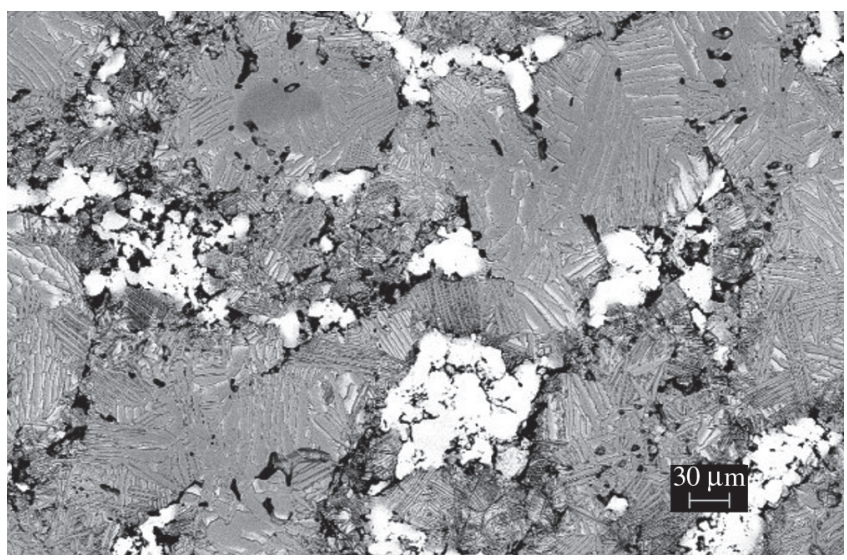

(b) $1100{ }^{\circ} \mathrm{C}$

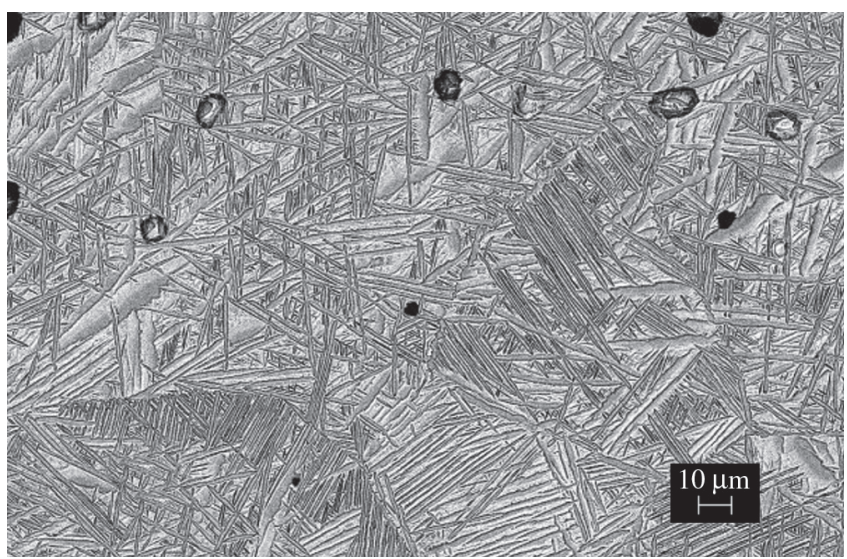

(d) $1500{ }^{\circ} \mathrm{C}$

Figure 2. Microstructure of P/M-Ti-13Nb-13Zr alloy with the temperature increase, between 900 to $1500{ }^{\circ} \mathrm{C}$. 
However, although the niobium, in compositional terms, can be considered a neutral element, it strongly acts in the $\beta$-phase stabilization, significantly decreasing the $\beta$-transus temperature.

X-ray diffraction analysis revealed only peaks of the $\alpha$ and $\beta$ titanium phases, not being identified peaks related to the hydride, oxide or intermetallics, (Figure 4).

\section{Conclusions}

- The blended elemental P/M process demonstrated to be efficient for the alloys production. The samples have presented high densification and adequate microstructure;

Table 2. $\mathrm{Ti}, \mathrm{Nb}$ e $\mathrm{Zr}$ contents in the areas analyzed (EDS).

\begin{tabular}{cccc}
\hline Site & $\mathrm{Ti}($ wt. $(\%))$ & $\mathrm{Nb}($ wt. $(\%))$ & $\mathrm{Zr}($ wt. $(\%))$ \\
\hline (1) $\alpha$-phase & 85.27 & 15.03 & 9.69 \\
(2) $\beta$-phase & 62.65 & 22.09 & 15.26 \\
\hline
\end{tabular}

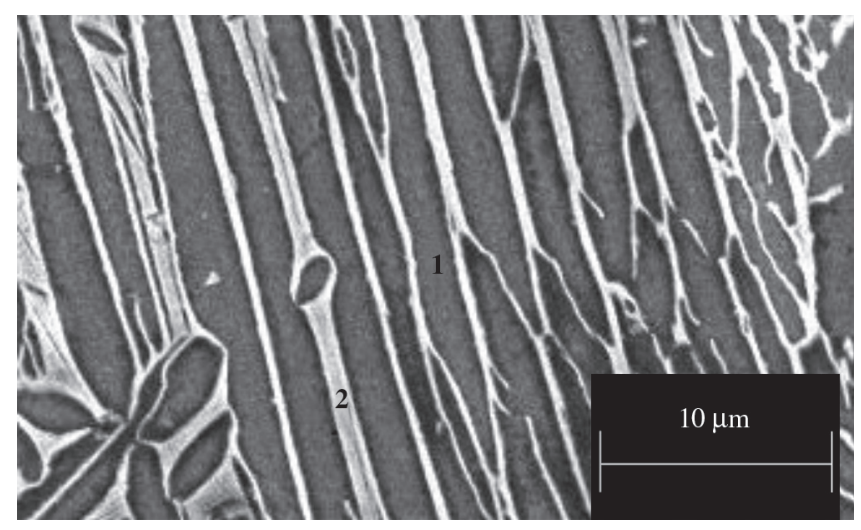

Figure 3. $\alpha$-phase (1) and $\beta$-phase (2) areas analyzed by EDS in Ti-13Nb-13Zr alloy.

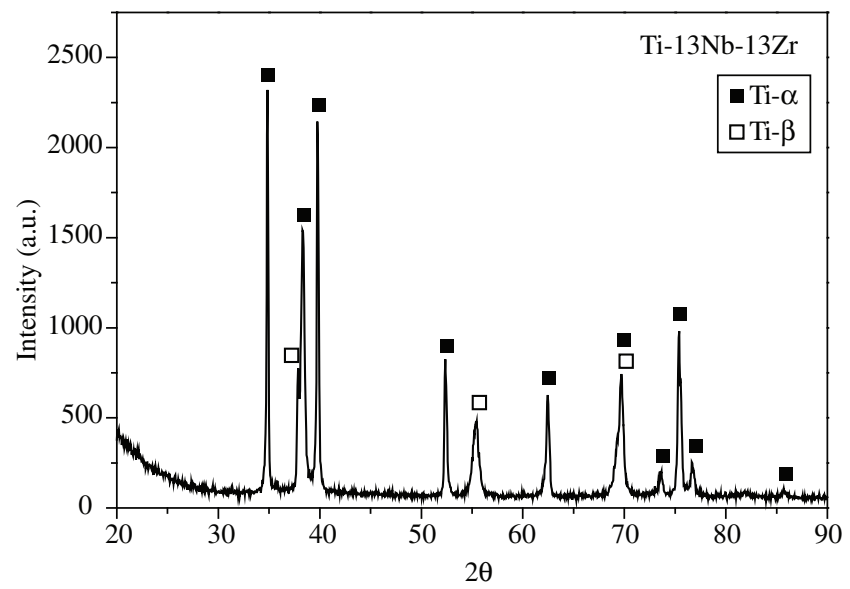

Figure 4. X-ray diffraction pattern of Ti-13Nb-13Zr alloy after sintering at $1500{ }^{\circ} \mathrm{C}$.
- Due the complete dissolution of the alloys elements in the titanium matrix, a good combination of microstructure, mechanical properties and densification could be reached;

- The sintering parameters provided a homogeneous microstructure, with low porosity and contamination. Higher pressing temperatures or longer holding times can lead to intensive grain growth;

- The high densification reached demonstrates not to be essential a hot pressing stage to the parts production in applications where it is not necessary high mechanical properties and performance;

- In both alloys, the Widmanstätten structure grows with the dissolution of the $\beta$-stabilizers particles ( $\mathrm{Nb}$ and $\mathrm{V})$, that act as $\beta$-phase nucleator agent, by increase of the sintering temperature;

- The microstructural development and hardness values showed by the P/M-Ti-6Al-4V samples are next to those obtained by conventional techniques. This way, components produced by $\mathrm{P} / \mathrm{M}$ can act as low cost substitute in some specific aerospace application;

- The microstructural development of the Ti-13Nb-13Zr obtained during sintering is adequate to the flexibility improvement in the parts produced by $\mathrm{P} / \mathrm{M}$ techniques becoming them more resistant to shock and explosion damage (e.g., military and aerospace applications); and

- The hardness values observed in the samples are within the range used in commercially manufactured parts produced by powder metallurgy techniques.

\section{References}

1. Froes FH, Eylon D. Developments in titanium powder metallurgy. Journal of Metals. 1980; 32(2):47-54.

2. Boyer RR. Aerospace applications of beta titanium alloys. Journal of Metals. 1994; 46(7):20-23.

3. Allen P. Titanium alloy development. Advanced Materials \& Processes. 1996; 10:35-37.

4. Andersen PJ, Alber NE, Thellmann EL. P/M Titanium reduces aerospace components costs. Precision Metals. 1980; 104:34-41.

5. Donachie MJ. Titanium: a Technical Guide. revised ed. Ohio: ASM Metals Park; 1988.

6. Wildgoose P. Powder metallurgical innovations for improved hotsection alloys in aeroengine applications. Powder Metallurgy. 1981; 24(2):75-86.

7. Froes FH. The production of low-cost titanium powders. Journal of Metals. 1998; 50(9):41-43.

8. Mitkov M, Bozic D. Hydride-dehydride conversion of solid Ti6A14V to powder form. Materials Characterization. 1996; 37(2):53-60.

9. Froes FH, D. Eylon. Powder metallurgy of titanium alloys- A review. Powder Metallurgy International. 1985; 17(4):163-167.

10. Henriques VAR, Silva CRM, Bressiani JC. Utilização de técnicas de metalurgia do pó (M/P) na obtenção da liga Ti-13Nb-13Zr. Metalurgia e Materiais. 2003; 59(532):7-10. 